[Hipkins, R. (2005). The NCEA in the Context of the Knowledge Society and National Policy Expectations. New Zealand Annual Review of Education, 14, 27-38]

\section{The NCEA in the Context of the Knowledge Society and National Policy Expectations}

\author{
ROSEMARY HIPKINS
}

\section{Abstract:}

The introduction of the National Certificates of Educational Achievement (NCEA), as the key school-based components of New Zealand's National Qualifications Framework (NQF) has been accompanied by controversy around a range of issues. It seems that much of the debate has centred on surface level symptoms, and has not probed the deep underlying causes of the tensions. In this article I locate the assessment changes of the NOF/NCEA within the "knowledge society" imperative for "life-long learning" and explore consequences of the expectation that assessment can serve this overarching goal at the same time as the results are used for accountability purposes - that, is for "raising standards". The tensions created by these conflicting expectations must be confronted openly before they can be resolved.

$n$ the New Zealand senior secondary school there has been a staged implementation of changes to assessment for national qualifications. The previous norm-referenced examinations at Year 11 (School Certificate) and Year 13 (Bursary), together with the internally assessed Sixth Form Certificate issued in Year 12, have been replaced with standards-based National Certificate of Educational Achievement awards (NCEA), at all three of these senior secondary school year levels. These certificates comprise the key school-based qualifications within a wide-ranging "seamless" National Qualifications Framework (NQF). Implementation of the NCEA began at Year 11 in 2002, with Level One being awarded for the first time. In 2003 the NCEA was implemented in most schools at Level Two/Year $12 .{ }^{1}$ In 2004, Level Three of the award was assessed for the first time, together with an optional "scholarship" award beyond Level Three NCEA standards for the most able students.
This sweeping set of reforms has been controversial. As is to be expected when such thoroughgoing reform of a long-established assessment tradition is undertaken, some flaws in the design of the system have been exposed in practice. These clearly warrant ongoing attention, or they run the risk of undermining the potential benefits outlined below. However, these issues are not the focus of this article. Rather it is my intention to explore some largely tacit assumptions that appear to underlie critiques aimed at abolishing the NCEA and reinstating the previous assessment system. I argue that some aspects of the critical comparison seing made between old and new assessment systems are unfair. The NQF/NCEA is expected to serve a wider range of policy purposes than the previous norm-referenced examinations were. I analyse tensions that are created when traditional and newer policy purposes are in conflict with each other. These expectations and tensions would not go away if the old system were to be restored. For this and other reasons, it will be argued that our combined intellectual efforts and practical expertise would be better spent addressing the tensions in the current system.

\section{Setting Assessment Changes in the Context of the "Knowledge Era"}

Some critics appear to see the NCEA as a foolish, unnecessary experiment. These people may call for restoration of the previous national examinations, or they may advocate adoption of an international examination of a similar type - for example, the Cambridge International Examinations, from the examinations board of the university bearing that name in the United Kingdom. However an analysis of international policy imperatives suggests there are good reasons why two successive New Zealand administrations have initiated and persisted with this radical overhaul of the way in which senior secondary school students are assessed for qualifications. In a synthesis of trends in assessment in the final decade of the twentieth century, Broadfoot and Black (2004) identify the rapid evolution of a "global economy" in the "knowledge era" as the source of the imperative for assessment changes in education internationally. So the first point to be made is that New Zealand is not on its own in facing these challenges. But is what we are attempting an appropriate response to the challenges of the knowledge era? This analysis begins by a brief consideration of the broad sweep of the social changes of this new era, at least as these relate to school assessment systems. 
Gilbert (2005) has analysed the implications of "knowledge era" changes for education in New Zealand. She comprehensively documents arguments that have been made for change on both economic and social justice grounds. The case for making educational changes to sustain and improve the "knowledge economy" has been more often discussed in public. Findings from the Science and Innovation Advisory Council (SIAC) are typical of the rhetoric that describes the importance of better and more broadly based education to ensure future economic prosperity:

The students of the future will come of age in a world in which they will be increasingly likely to employ themselves rather than be employed by others. It is likely that they will have several careers rather than one job for life. It is imperative that our education system, at all levels, is focused on developing the whole person. We need people who are able to take their education and make their lives out of it, confident that they have a sound foundation on which to build their future; people who are agents of change rather than its victims. (Science and Innovation Advisory Council, 2002, p. 39)

The complex process of taking an education and "making a life out of it" is often encapsulated in the seductively simple phrase "lifelong learning". Recently Codd et al. (2002) named lifelong learning as one of the key themes they found in a synthesis of future-focused research on teaching and learning. Black and Broadfoot (2004) similarly identified this as a key theme of specifically assessment-focused research. Interestingly for our purposes, Codd et. al. also found that most educationalists seemed to expect gradual transformation rather than radical change in education. I believe that this policy direction does require quite radical change in our assessment systems. Why is it that things could not stay as they were?

Gilbert (2005) discusses the implications for the existing school system if all students are to receive an education that will stand them in good stead for lifelong learning. To meet this goal, it is first necessary to keep students in school longer, to boost levels of literacy, including cultural and critical literacy, and to foster in all of them a sense of themselves as successful learners. While these may not seem particularly revolutionary goals, the picture becomes problematic when assessment for qualifications is considered. As Gilbert documents, norm-referenced national examinations were originally devised to sort students, in order to ration access to the limited number of places available in higher education. Only those students considered worthy of further learning were encouraged to stay at school once they had received a basic level of education. National resources were better employed in sending those who would not benefit from higher education out to work and, usually, away from further learning opportunities. In the industrial era this sorting made economic sense to most people. However critical curriculum commentators documented the social injustices perpetrated when access to certain types of cultural knowledge impacted on examination success, and hence on the sorting process (Apple, 2004). Gilbert argues that the social stakes are now much higher in the new, knowledge era. There are fewer unskilled jobs. Work in these types of jobs is increasingly carried out by casual labour, and shifted around the globe to the cheapest labour sources. Since "sweatshop" working conditions are never likely to be acceptable to most New Zealanders, we need to keep creating new kinds of employment opportunities, and educating the skilled workers who will do the work. In this way social justice and economic interests become entwined.

We cannot increase education levels while at the same time continuing to reject around half the student population just as they are beginning to mature as people and as learners. For this reason alone, the knowledge era changes briefly outlined above present a compelling political imperative for corresponding changes in assessment. What then, should be the broad thrust of such change if it is to encourage and support ongoing learning?

\section{Lifelong Learning and the Transformation of Persons}

The rapidity of change in the knowledge era is one reason that developing "knowledge and skills for lifelong learning" is now essential. But how can we plan for teaching predetermined skills and knowledge when we can be reasonably certain that students will need to cope in future conditions we cannot even conceive? Barnett suggests that an education that develops "the human being as such" $(2004$, p. 255) is the best way to address this dilemma. He points out that there are certain dispositions that seem to equip some people better than others to cope when the unimaginable is happening to them. He lists these dispositions as carefulness, thoughtfulness, humility, criticality, receptiveness, resilience, courage and stillness. This idea that learning should be about the transformation of one's "being" as much as it is about "knowing" is supported by both neo-pragmatist educators and socio-culturallearning theorists (see, for example, Lave \& Wenger, 1991; Packer \& Goicoechea, 2000; Delandshere, 2002; Girod \& Wong, 2002). 
Delandshere points out that the predominant assessment question has always been, "what do students know?" In her view, the fundamental question ought to be "what does it mean to know?" (p. 1462, emphasis added).

This is a challenging question indeed. But it is important not to read an emphasis on the ontological shift to "being" as representing a rejection of the importance of "knowing" and of knowledge. On the contrary, this aspect of learning also needs close scrutiny, because another theme of knowledge era research is that the meaning of knowledge and knowing - the very stuff of teaching and learning - is also changing. Traditionally knowledge has been viewed as a noun - a product to be gained and stored in case of future need, and this acquisition is what has been assessed. Gilbert (2005) documents how, in the knowledge era, knowledge is widely seen as being more like a verb - something that is not a "thing in itself" but is the raw material with which to do things. Rather than being valued for its own sake, knowledge is valued for its performativity - that is, what it can do. In this new view, students of all ages need to be performative - to do things that create genuinely new knowledge. Here knowledge-era economic developments (ways knowledge works in the world) and newer theoretical viewpoints on learning come together. "What does it mean to know" relates more to what learners can do with their learning, and with rich insights into how they came to develop their learning, than to what they have stored up in their minds for future recall (Delandshere, 2002).

The argument for a focus on active knowing rather than passive knowledge is grounded in sociocultural views of learning (Lave \& Wenger, 1991; Delandshere 2002; Lemke, 2002). The proponents of these views seriously challenge the mind/body dualism that treats learning as the solitary act of one brain (with or without support from more knowledgeable others). For socioculturalists, learning is situated in social contexts. Any individual's memory can reside at least partially in objects and surroundings (Lemke, 2002). This accords with the knowledge era perspective that learning and innovative knowledge production often originate in multi-disciplinary teams rather than in the work of isolated individuals (Gilbert, 2005). Thus part of developing the "whole person" entails learning to work together, to share ideas and expertise, and to jointly build new understandings. Norm-referenced examinations, with their focus on knowledge recalled in formal examinations, under conditions that separate the learner from the contexts of their actual knowing, clearly never could assess such situated, collaborative knowledge building. Can the NCEA do any better? Perhaps, but not without considerable ongoing study and the development of some new standards. We have a long way to go before we can change the expectation that "rigorous" assessment is necessarily an individual act, and that working together to demonstrate learning is "cheating".

Another way that the imperative for assessment change is manifested in policy initiatives is through talk about "learning pathways". Keeping all students at school for longer does not have to mean all should be prepared as if they were going on to university study. Rather, a range of types of learning options and pathways should be offered. Traditional examinations provided a "one-size tests all" model in which students were ranked against each other on the basis of mastery of one pre-specified body of content. Because the qualifications gained from these examinations, particularly the Bursary examination, sorted out students who would be allowed to go on to university, the "one size" was inevitably focused towards traditional tertiary academic requirements. Examinations as they were traditionally conceived could never have been pressed into service as means of individualising students' learning for different pathways. By contrast, the Minister of Education has recently described the NCEA as providing "a range of new tools to customise programmes to meet individual learner needs" for career pathways that do not necessarily include university study (Mallard, 2004). On this score, the NCEA fares rather better than it does on the vexed issue of group assessments. The research into Learning Curves currently being carried out at the New Zealand Council for Educational Research (Hipkins \& Vaughan, 2002; Hipkins et al., 2004), has found that multiple ways of progressing through the senior secondary school are indeed opening up. Many students who might traditionally have done "applied" courses in lieu of those assessed by national examinations are thriving in various new courses. These courses often display at least some features congruent with knowledgeera arguments for effective learning - for example they are often are set in contexts of relevance to the students' lives (Hipkins, 2004). There is a growing body of evidence to suggest the NCEA, in combination with other NQF initiatives, has so far been a success in opening up new learning pathways through the senior secondary school.

Recent work on learning theory and the knowledge era also poses serious challenges for traditional assessment practice. As Delandshere 
(2004) points out, there is a "conceptual vacuum" (p. 1463) where assessment theory has not kept pace with recent developments in learning theories. She asserts that even quite elaborate models of assessment - those which purport to draw on more advanced cognitive or constructivist perspectives - have not escaped their behaviourist roots:

[these theories and models] ... rest on the same determinist assumption .... The information (or input) received from the environment determines the cognitive processing and the person's response ... such determinism makes it possible to control people's

learning. (Delandshere, 2002, p. 1470)

This claim signals another very difficult tension. As outlined above, the future-focused literature suggests that "lifelong learning" requires that persons actively transform themselves through authentic (for them), situated learning experiences and opportunities for knowledge building. Yet we expect this process to be kick-started in traditional industrial-age schools, where students are still processed in "batches" we call classes (Gilbert, 2005) and tested against the same standardised set of deterministic "learning outcomes". The tensions generated become even more acute when teachers and schools are held accountable for their "success", measured in terms of "raising standards".

\section{Lifelong Learning Or Raising Standards - Can We Have Both?}

Accompanying the call for lifelong learning, there has been a policy focus on improving the achievement of the students located at the "tail" of assessment statistics for national examinations. "Closing the gaps", "really raising achievement", "making a real difference", and "no child left behind" are examples of the sorts of catch phrases that accompany these policy initiatives. ${ }^{2}$ Typically they are focused on improving the effectiveness of teachers and schools. But what does this rhetoric really mean, and can the NCEA deliver the desired improvements in teaching, and hence in learning?

In her evaluation of the reform of assessment for "second chance" vocational education in the UK, Ecclestone (2002) noted how easily people can talk past each other when they ascribe different meanings to the term "standards". On the one hand upholding standards is a code for the maintenance of tradition and assessment by conventional "rigorous" examinations. On the other hand, "standards" can mean the specification of what is to be learnt, for the purposes of subsequently determining how well actual learning has succeeded, as in the NCEA's "achievement" and "unit" standards. "The differences in meaning become blurred when standards-based assessment is used as the policy instrument for "raising standards" in the accountability sense.

The mismatch between maintaining "rigorous" traditional standards and future-focused views of lifelong learning has been outlined above. What of the second meaning for "standards"? In particular, what are the implications of holding teachers accountable for their work in preparing students to be assessed against pre-specified standards that are intended to increase the range of aspects of learning that can be assessed? Here, a related set of tensions is at work when this meaning of "raising standards" is intended. Again there is a mismatch between accountability/sorting expectations and the (at least implicit) learning theories that underpin lifelong learning rhetoric. The NCEA is implicated in new calls for teacher accountability. The Learning Curves research at NZCER has found that NCEA data may be used to compare the results achieved by students taught by different teachers within a departmental team (Hipkins et al., 2004). That is not inherently new. It has always been possible to compare students' gross marks from external examinations. However results can now be broken down so that within-subject patterns of achievement can be compared for the various standards for which students were entered. At least in some schools, the more detailed reporting is being used to compare teacher efficacy - both overall and in teaching specific topics - and to set goals for teachers' personal improvement in "raising the standards" of their students. What is a teacher to do? If they are to be compared with other teachers who are doing essentially the same job, their most sensible option seems to be to "raise standards" by resorting to tried and true methods of intensive coaching of groups of students, who all sit the same assessments at the same time. In part because of this type of pressure, the potential of the NCEA to provide flexibility in learning and assessment for students with different learning needs has yet to be fully realised in practice.

Delandshere, writing about a parallel teacher accountability dilemma in the American context, poses the following critical questions:

When the same test is given to all sixth graders in a state to find out whether their educational experiences yield similar achievements, is it because we are working from a theory stating that if students have all been taught the same thing, they will learn it in the same way at 
the same time? It seems unlikely that any educator would articulate such a theory. Yet without this perspective, how can current forms of state-mandated assessment be justified? In this practice a great disparity seems to exist between educational and political assumptions. (p. 1480)

Rightly or wrongly, schools are also often judged by their students' examination successes, particularly when "league tables" of relative performances are publicised and discussed in the media. Norm-referenced examinations yielded data that were relatively straightforward to process for comparative purposes. But because student achievement is now reported in terms of the learning criteria set by the achievement and unit standards, statistical translations are required if "one mark" normative comparisons are to be made. Potentially multiple types of translations and comparisons are possible, so these translations require considerable statistical acumen and very careful thought about what is really going on. For example, in one small project, it was found that students' achievement patterns in the NCEA at Year 11/Level One were linked to their attendance at Year 9, and this effect seemed to interact with the pedagogical innovation that was the focus of the research (Bartlett, 2005).

When achievement data for a whole cohort are aggregated, decisions related to the interests of students, and the nature of the reporting of their individual achievement, come into direct conflict with data-driven accountability issues. The furore in late 2004 over non-reporting of results when students have not achieved particular standards provides a good example of this tension in action. On the one hand it seems perfectly reasonable to claim that personal records of learning belong to every student, individually, and show what they can do in a positive way. (Here is the lifelong learning policy imperative at work.) On the other hand, school-level achievement statistics used for accountability purposes are obviously distorted by the omission of these data. Again this difficult tension cannot be resolved until it is openly explored without acrimony.

\section{Where to From Here?}

Two successive New Zealand governments have contributed to the development of a new assessment paradigm as a response to the challenges facing secondary school education in the "knowledge era". As we have seen, the solutions developed as the reforms have evolved are fraught with unresolved tensions. Because these challenges are not going to go away, and indeed are likely to become ever more acute, I would argue that we cannot afford to retreat to the seductive but illusory certainties of past assessment traditions. While both policy and practical implementation tensions are currently much in evidence, and the break with tradition has been difficult for many to cope with, progress has been made. This is not the time to turn back.

Can we find ways to reduce the tensions between conflicting purposes for national assessment without compromising the integrity of the data gathered? The contributors to Wilson (2004) think so. This edited book includes several thought-provoking suggestions for deliberately designing more sophisticated tasks that can meet both ongoing learning and accountability goals. For example, LeMahieu and Reilly suggest that the process of designing assessments that can reduce learning/accountability tensions should begin with assessment of tasks that serve teaching and learning purposes. This is because assessment data that effectively inform ongoing learning need to be rich in detail and relevant to the context. From this rich data base the more streamlined data needed for accountability purposes could be extracted and abstracted. But they note that this would only work if the learning-focused assessment tasks were cleverly designed with accountability ends in mind. Such design, they say, could only be achieved by assessment experts and classroom teachers working together, with mutual trust in each other's respective areas of expertise. Their suggestion accords with Delandshere's call for assessment to be conducted as an inquiry process, but her warning that assessment theory lags far behind recent developments in learning theories should be noted (2002, pp. 1463). Answering the question "what does it mean to know?" still seems an elusive assessment goal. Perhaps this is the first gap that needs to be closed if we are to stand a better chance of meeting changing expectations of schools and of effective learning for the knowledge age.

Notes

1. In response to workload pressures this was made optional, but most schools went ahead rather than face implementation at two levels in 2004.

2. "No child left behind" is the American equivalent of "closing the gaps"this is another pointer to parallels between New Zealand's assessment challenges and those being addressed in other nations. 
3. Achievement standards specify four levels of achievement: not achieved, achieved, achieved with merit or achieved with excellence. Unit standards are competency based and are either achieved or not achieved.

\section{References}

Apple, M. (2004). Ideology and Curriculum: Third Edition. New York: Routledge Falmer.

Barnett, R. (2004). Learning for an unknown future. Higher Education Research and Development, 23(3), 247-260.

Bartlett, J. (2005). Developing independent learners: The planning and implementation of an inquiry-based curriculum integration programme at Kuranui College. Wellington: New Zealand Council for Educational Research.

Broadfoot, P., \& Black, P. (2004). Redefining assessment? The first ten years of assessment in education. Assessment in Education, 11(1), 7-27.

Codd, J., Brown, M., Clark, J., McPherson, J., O’Neill, H., O’Neill, J., Waitere-Ang, H., \& Zepke, N. (2002). Review offuture-focused research on teaching and learning. Wellington: Ministry of Education.

Delandshere, G. (2002). Assessment as inquiry. Teachers College Record, 104(7), 1461-1484.

Ecclestone, K. (2002). Learning autonomy in post-16 education: The politics and practice of formative assessment. London and New York: Routledge Falmer.

Gilbert, J. (2005). Catching the knowledge wave: "Knowledge society" developments and the future of public education in New Zealand. Wellington: New Zealand Council for Educational Research.

Girod, M., \& Wong, D. (2002). An aesthetic (Deweyan) perspective on science learning: Case studies of three fourth graders. The Elementary School Journal, 102, 219-224.

Hipkins, R. (2004, April). Changing subjects for changing times. Paper presented at the PPTA Conference, "Charting the Future", Wellington.

Hipkins, R., \& Vaughan, K. (2002). From cabbages to kings: Interim research report - first year of Learning Curves: Meeting student needs in an evolving qualifications regime. Wellington: New Zealand Council for Educational Research.
Hipkins, R., Vaughan, K., Beals, F., \& Ferral, H. (2004). Shared pathways and multiple tracks. Interim research report - second year of Learning Curves: Meeting student learning needs in an evolving qualifications regime. Wellington: New Zealand Council for Educational Research.

Lave, J. \& Wenger, E. (1991). Situated learning: Legitimate peripheral participation. Cambridge, MA: Cambridge University Press.

Lemke, J. (2002). Becoming the village: Education across lives. In G. Wells \& G. Claxton (Eds.), Learning for life in the 21st century (pp. 34-45). Oxford: Blackwell.

Mallard, T. (2004, April 20). Education for the changing world. Address to the PPTA Conference, "Charting the Future", Wellington.

Packer, M., \& Goicoechea, J. (2000). Sociocultural and constructivist theories of learning: Ontology, not just epistemology. Educational Psychologist, 35, 227-241.

Science and Innovation Advisory Council (SIAL). (2002). New Zealanders, innovators to the world. Turning great ideas into great ventures. An innovation framework for New Zealand. Wellington: Science and Innovation Advisory Council.

Wilson, M. (Ed.). (2004). Towards coherence between classroom assessment and accountability. The 103rd Yearbook of the National Society for the Study of Education, Part 2 (pp. 89-202). Chicago: University of Chicago Press.

\section{The author}

Rosemary Hipkins is a senior researcher at New Zealand Council for Educational Research. She is interested in future-focused change in education and is a member of the Ministry of Education Reference Group for the Curriculum Project currently being undertaken. Rosemary is leading research into selected aspects of curriculum and assessment practice in secondary schools as the NCEA qualifications reforms are being critiqued and refined and she has an interest in the effective use of ICT across all curriculum levels. 